\title{
Marginal bone loss around dental implants with various types of implant-abutment connection in the same patient
}

\author{
Jolanta Szymańska', Piotr Szpak² \\ ${ }^{1}$ Department of Paedodontics, Medical University of Lublin \\ 2 Individual Dental Practice "Dentistry Implantology Piotr Szpak", Białystok
}

Szymańska J, Szpak P. Marginal bone loss around dental implants with various types of implant-abutment connection in the same patient. J Pre-Clin Clin Res. 2017; 11(1): 30-34. doi: 10.26444/jpccr/74465

\begin{abstract}
Introduction. One of the criteria of implant therapy success is marginal bone loss. The objective of the study was to assess the correlation between peri-implant marginal bone loss and implant-abutment connection systems used in the same patient, as well as other specific characteristics of implant treatment. The initial research hypothesis assumed that there was no difference in marginal bone loss around implants with different implant-abutment connection systems placed in the same patient.

Materials and method. Marginal bone loss was assessed around implants with two different types of implant-abutment connection: with conical (Type I) and with internal hexagonal (Type II) in the same patient. The study included 28 patients aged 37-66 years.

Results. Marginal bone loss around Type I implants was $0.112 \mathrm{~mm} / \mathrm{month}$ before loading with prosthetic restorations, and $0.010 \mathrm{~mm} / \mathrm{month}$ after loading, while for Type II implants it reached, respectively, $0.123 \mathrm{~mm} / \mathrm{month}$ and $0.030 \mathrm{~mm} / \mathrm{month}$. Marginal bone loss after loading with prosthetic restorations was 11 times lower for Type I implants and 4 times lower for Type II implants. Evaluation of marginal bone loss in the studied patient groups was made on the basis of orthopantomographic radiographs.

Conclusions. Implants with conical implant-abutment connection are significantly more favourable to osseointegration than those with internal hexagonal connection. As marginal bone loss is faster before loading implants with prosthetic restorations than after loading, it is advisable to consider early loading if the necessary clinical conditions are met.
\end{abstract}

\section{Key words}

dental implants, abutment type, marginal bone loss, humans

\section{INTRODUCTION}

Knowledge of factors that affect implant survival and successful treatment at its every stage may significantly contribute to the achievement of therapeutic success. Papaspyridakos et al. [1] proposed a list of factors that lead to the complete success of implant treatment. Therapeutic success is defined as the correct function of the whole complex composed of implants, prosthetic restorations and the surrounding hard (bone) and soft (mucosa and gum) tissues. The particular criteria of maximum success include: implant immobility, absence of pain, and bone loss below $1.5 \mathrm{~mm}$ (observed on radiographs). It is also suggested that the success of implant treatment is guaranteed if the therapy follows the principles of bone stability and healthy soft tissues [1].

\section{OBJECTIVE}

The main objective of the study was to assess the correlation between peri-implant marginal bone loss and implantabutment connection systems used in the same patient, as well as other specific characteristics of implant treatment.

Address for correspondence: Jolanta Szymańska, Department of Paedodontics, Medical University of Lublin, Karmelicka 7, 20-018 Lublin, Poland

E-mail: szymanska.polska@gmail.com

Received: 10 May 2017; accepted: 7 June 2017
The initial research hypothesis assumed that there was no difference in marginal bone loss around implants with different implant-abutment connection systems used in one patient.

\section{MATERIALS AND METHOD}

Study population. The study involved 28 patients (11 male and 17 females) treated with dental implants, aged 37-66 years (mean age: 55.8 ). The maximum observation time from implantation was 46 months. The patients were treated at the Non-Public Health Centre Dent-Plast in Białystok, Poland.

Characteristic of the studied implant systems. The patients were restored with two types of implants with different implant-abutment connection. Type I were implants with Morse taper connection (DENTSPLY Friadent ANKYLOS ${ }^{*}$ ), Type II included implants with internal hexagonal connection (MIS Seven ${ }^{\circledR}$, Alpha-Bio SPI and $\mathrm{DFI}^{\oplus}$, Adin Tuareg RP ${ }^{\oplus}, \mathrm{AB}$ $12^{\circ}$, DENTSPLY Friadent Xive ${ }^{\circ}$. The patients received 91 Type I implants (Ankylos ${ }^{\circ}$ ) and 149 Type II implants (MIS Seven : 36 , Alpha-Bio SP and DFI': 73, Adin Tuareg RP ${ }^{\oplus}: 14$, DENTSPLY Friadent Xive ${ }^{\bullet}: 8$ ).

Characteristic of the implant treatment. The total number of implants in the study was 240, including 91 Type I and 149 Type II implants. At least one implant of each type was 
placed in every examined patient. The shortest observation time was 4.9 months, the longest 46 months. Type I implants were loaded on average at 10.2 months after implantation (between 5.0 and 22.1 months).

Marginal bone loss was evaluated before and after loading implants with prosthetic replacement. For Type I, 139 measurements of peri-implant marginal bone were performed, while for Type II the number of measurements was 277.

During the therapy, two implants did not osseointegrate and were removed on uncovering; those implants were not taken into account in the statistical analyses. One of the removed implants was DENTSPLY Friadent ANKYLOS ${ }^{\circledast}$ (Type I), the other - Alpha-Bio DFI ${ }^{\odot}$ with hexagonal connection (Type II).

Surgical techniques. The procedure of implant placement was performed using the flap method. All implants underwent closed healing. To improve bone quality at the implantation sites, the procedures of lifting and restoration of jaw sinuses were carried out using bone substitutes or grafting materials. The second stage of surgical treatment included the uncovering of implants and placing healing caps for 3-12 days.

Prosthetic restorations. Both provisional and permanent restorations were applied in the implant treatment. Without loading permanent implants, provisional prosthetic restorations, such as crowns, bridges, and removable dentures resting on provisional implants, were provided immediately after surgical procedure. Prosthetic loading of implants was always functional, both for provisional and permanent restorations. The patients used provisional prosthetic restorations for the average period of two weeks to two months. The inserted implants were loaded with (functional) prosthetic restoration between 5.0 and 26.5 months after implantation (mean time 10.6 months, median 9.3 months). Type I implants were loaded between 5.0 and 26.5 months (after 10.2 months, on average), while Type II implants were loaded between 5.0 and 22.1 months (after 10.8 month, on average) after implantation. In the case of Type II implants, the procedures involved connections without platform-switching.

Permanent prosthetic restorations were crowns, crown blocks and porcelain bridges resting on the Cr-Co prosthetic alloy. Full acrylic dentures were strengthened with a Cr-Co skeleton, supported by bars or telescopes. Crowns, crown blocks and bridges were supported by titanium abutments. Dentures were retained using Cr-Co bars and telescopic titanium abutments. Prostheses were placed on implants using prosthetic bars and telescopic joints. Crowns and bridges were made of porcelain and provided with a $\mathrm{Cr}-\mathrm{Co}$ alloy prosthetic framework.

After the application of prosthetic restorations, pantomographic radiographs were taken to evaluate the stability of implants, bone-to-implant interaction and periimplant bone.

Techniques of peri-implant bone loss measurement. Pantomographic radiographs were taken in order to qualify patients for an appropriate implant procedure and to monitor the treatment. Both analogue (Siemens OP5 ${ }^{\circledR} \mathrm{X}$-ray, Munich, Germany) and digital (Planmeca ProMax ${ }^{\circledast}$ X-ray, Helsinki,
Finland) techniques were used. The evaluation of marginal bone loss in the studied patient groups was made on the basis of orthopantomographic radiographs. Pantomographic radiographs were taken after the surgical procedure of implant placement and during the following 46 months. At different stages of implant treatment the level of marginal bone around implant neck was assessed by referring each measurement to the initial state, i.e. to the bone level immediately after implantation.

To evaluate marginal bone around implants, a line adjacent to the highest point (point A) of the hard bone edge was drawn perpendicularly to the long axis of the implant (Fig. 1). Next, point B was identified at the border of the first bone-to-implant contact as measured from the implant neck. Subsequently, a line perpendicular to the line through the hard bone edge (through its highest point - point A) was drawn through point $B$, and point $C$ was determined. The measurements of the line segment between points $B$ and $C$ during the implant treatment showed the status of marginal bone around implant, indicating bone loss, growth or the absence of changes over time. It must be noted that the measurement of the B-C segment was made on the mesial and distal aspects of the implant, and its final value was the mean of two measurements. The measurement results were expressed in millimetres ( $\mathrm{mm})$ [2].

The digital pantomographic radiographs, taken with Planmeca ProMax ${ }^{\oplus}$, were assessed using the appropriate software (Planmeca Romexis ${ }^{\oplus}$ 2.6.0.R, Helsinki, Finland). The analogue radiographs, taken with a Siemens $\mathrm{OP} 5^{\circ}$ using radiographic films (Kodak ${ }^{\circledast}$, New York, USA) were assessed with a negatoscope. The distance between points $\mathrm{B}$ and $\mathrm{C}$ was calculated on enlarged radiographs (1.25x). Final measurement results were given after verification of the enlargement (Fig. 1).

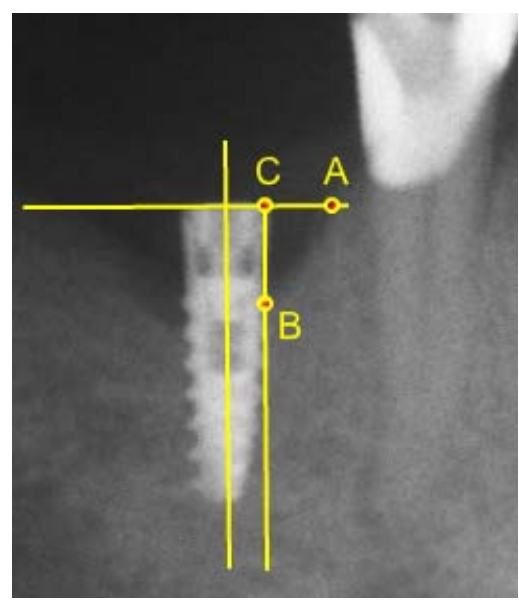

Figure 1. Measurement of vertical loss of periimplant marginal bone on a pantomographic radiograph

Evaluation of marginal bone status included three conditions: unchanged marginal bone $(0 \mathrm{~mm})$, marginal bone loss (positive value expressed in $\mathrm{mm}$ ), and marginal bone growth (negative value expressed in $\mathrm{mm}$ ).

Statistical methods. Correlations between the status of periimplant marginal bone and the selected characteristics of the implant were evaluated using eneralised linear models. The 
parameters of the models were determined with Generalised Estimating Equation (GEE), as the measurements of the same implants were repeated, and the same patient was restored with several implants. The GEE method enabled analysis of patients for whom the numbers of repeated measurements differed $[3,4]$.

The independent variables in GEE model were: type of implant (Type I implants were the reference), time between implantation and implant loading with prosthetic restoration (time increase by 1 month), time between implant loading with prosthetic restoration and the measurement of bone loss (time increased by 1 month).

Limitations of the research model. The retrospective evaluation of peri-implant marginal bone status was made for two implant systems with different abutment structures. The observation time was up to 46 months, and the observation periods included in the model varied for different patients. In these circumstances, it was possible to evaluate only a tendency in the change that occurred in marginal bone around two implant types over time, and to determine differences between the levels of marginal bone change for those two types of implants.

The status of marginal bone around implants was evaluated during 46-month observation time divided into two periods: from the surgical procedure (implantation) to loading implants with prosthetic restorations, and from implant loading to the end of observation.

The adopted statistical models assumed a linear correlation between the peri-implant marginal bone change and time.

Assessment of bone loss around implants of two different types placed in the same patient enabled elimination of possible effects of individual differences on osseointegration. The authors of the presented study believe such a research model to be highly objective.

\section{RESULTS}

The change in peri-implant marginal bone before loading with prosthetic restorations was significantly correlated with the time from implantation, both for Type I and Type II implants (Tab. 1). The average marginal bone loss around implants before prosthetic loading was $0.112 \mathrm{~mm} / \mathrm{month}$ for Type I $(\mathrm{p}<0.0001)$, and $0.123 \mathrm{~mm} / \mathrm{month}$ for Type II $(\mathrm{p}<0.0001)$. The changes in marginal bone around implants after prosthetic loading were also significantly related to time, both for Type I and Type II implants (Tab. 1). After loading Type I implants with prosthetic restoration, marginal bone loss was $0.010 \mathrm{~mm} / \mathrm{month}(\mathrm{p}<0.012)$, while for Type II implants it was $0.030 \mathrm{~mm} / \mathrm{month}(\mathrm{p}<0.0001)$.

Table 2 presents the differences in bone loss around Type I and Type II implants from implantation to loading with prosthetic restoration and after loading. Marginal bone loss was assessed using the generalised lineal model. In the period from implantation to loading with prosthetic restoration, the mean marginal bone loss, averaged for both types of implants, significantly increased over time $(\mathrm{p}=0.0001)$. In this period, no statistically significant difference $(\mathrm{p}=0.190)$ between Type I and Type II implants was found. However, from the moment of loading to the end of 46-month observation period, marginal bone loss around Type II implants was significantly greater (by $0.696 \mathrm{~mm}$ ) from that around Type
Table 1. Marginal bone loss around Type I and Type II implants from implantation to loading with prosthetic restorations and after loading

\begin{tabular}{|c|c|c|c|c|c|}
\hline \multirow{2}{*}{$\begin{array}{l}\text { Observation } \\
\text { Period }\end{array}$} & \multirow{2}{*}{$\begin{array}{l}\text { Implant } \\
\text { type }\end{array}$} & \multirow{2}{*}{$\begin{array}{l}\text { Marginal } \\
\text { bone loss } \\
\mathrm{mm} / \text { month }\end{array}$} & \multicolumn{2}{|c|}{$95 \%$ confidence interval } & \multirow[t]{2}{*}{$p$} \\
\hline & & & $\begin{array}{l}\text { Lower } \\
\text { limit }\end{array}$ & Upper limit & \\
\hline \multirow{2}{*}{$\begin{array}{l}\text { Before loading with } \\
\text { prosthetic restoration }\end{array}$} & I & 0.112 & 0.073 & 0.151 & 0.0001 \\
\hline & II & 0.123 & 0.073 & 0.174 & 0.0001 \\
\hline \multirow{2}{*}{$\begin{array}{l}\text { After loading with } \\
\text { prosthetic restoration }\end{array}$} & I & 0.010 & 0.002 & 0.018 & 0.012 \\
\hline & II & 0.030 & 0.015 & 0.046 & 0.0001 \\
\hline
\end{tabular}

$p$ - level of significance

Table 2. Difference in marginal bone loss around Type I and Type II implants from implantation to loading with prosthetic restorations and after loading

\begin{tabular}{lccccc}
\hline Observation time & $\begin{array}{c}\text { Independent } \\
\text { variable }\end{array}$ & B & $\begin{array}{c}\text { 95\% confidence } \\
\text { interval }\end{array}$ & p \\
\cline { 2 - 5 } & & & $\begin{array}{c}\text { Lower } \\
\text { limit }\end{array}$ & $\begin{array}{c}\text { Upper } \\
\text { limit }\end{array}$ & \\
\hline $\begin{array}{l}\text { Before loading with } \\
\text { prosthetic restoration }\end{array}$ & Implant type II/I & 0.233 & -0.116 & 0.582 & 0.190 \\
\cline { 2 - 5 } & $\begin{array}{c}\text { Marginal bone loss } \\
\text { mm/month }\end{array}$ & 0.104 & 0.054 & 0.154 & 0.0001 \\
\hline $\begin{array}{l}\text { After loading with } \\
\text { prosthetic restoration }\end{array}$ & Implant type II/I & 0.696 & 0.425 & 0.968 & 0.0001 \\
\cline { 2 - 5 } & $\begin{array}{c}\text { Marginal bone loss } \\
\mathrm{mm} / \text { month }\end{array}$ & 0.024 & 0.013 & 0.035 & 0.0001 \\
\hline
\end{tabular}

B - regression model coefficient (marginal bone loss in $\mathrm{mm}$ ) (Reference categories for independent variables are printed in bold). $p$-level of significance

I implants $(\mathrm{p}=0.0001)$. In this period, the mean marginal bone loss, averaged for both types of implants, significantly increased over time $(\mathrm{p}=0.0001)$.

\section{DISCUSSION}

Few papers describe osseointegration around different types of implants inserted in the same patient $[5,6,7]$. The fact that in the presented study two types of implants were evaluated in the same patient, i.e. in unchanging conditions, guaranteed objectivity in the assessment of osseointegration process, and the differences in bone loss could not be explained by individual differences among the patients. The results obtained show that Type I implants osseointegrated better than Type II implants placed in the same patient.

Observation of peri-implant around marginal bone before loading implants with prosthetic restorations. This study shows that marginal bone loss around the compared implants before loading with prosthetic restoration was significantly related to time that elapsed from the implantation procedure both for Type I $(\mathrm{p}<0.0001)$ and Type II $(\mathrm{p}<0.0001)$ implants. In the observation period before loading, marginal bone loss around Type I implants reached the mean value of $0.112 \mathrm{~mm} / \mathrm{month}(1.344 \mathrm{~mm} /$ year$)$, while around Type II implants - $0.123 \mathrm{~mm} /$ month (1.476 $\mathrm{mm}$ /year). During this time, no statistically significant differences between the two types of implants were detected. Considering the average time from implantation to prosthetic loading, bone loss in this treatment period was assessed as $1.12 \mathrm{~mm}$ for Type I (average time from implantation to loading was 10 months) and 1.35 for Type II (average time from implantation to loading was 11 months). 
The differences in peri-implant marginal bone loss for different implant systems are regularly presented in numerous publications, which help researchers and practitioners to critically evaluate their own results. One such publications is the study by Chou et al. who, having assessed 1,500 DENTSPLY Friadent ANKYLOS ${ }^{\circledR}$ implants (Type I in the current study) in multicentre research, found that marginal bone loss from implantation to prosthetic loading was $0.81 \mathrm{~mm}(0.70 \mathrm{~mm}$ from implantation to uncovering and $0.11 \mathrm{~mm}$ from uncovering to loading). Bone loss for the tested implant system was lower than in other systems [8]. In the presented study, marginal bone loss that occurred from implantation to loading was higher; this, however, was due to the fact that the periods in question were 10 and 11 months. Thus, if clinical conditions are met, it may be advisable to consider prosthetic loading of implants after a shorter time from implantation.

Considering the whole osseointegration process, implants with hexagonal connections (Type II in this study) are believed to be less expedient than implants with conical connections. Bratu et al. compared bone loss for 72 MIS $^{\oplus}$ implants with internal and external hexagonal connections (subsystems: Lance ${ }^{\circledast}$ and Seven ${ }^{\circledast}$ ). Before prosthetic loading (after 4 months from implantation), bone loss around Lance ${ }^{\circledast}$ implants was $0-1.8 \mathrm{~mm}$ (mean: $0.91 \mathrm{~mm}$, i.e. $0.22 \mathrm{~mm} / \mathrm{month}$ ), and around Seven ${ }^{\circledast}$ implants $0-1 \mathrm{~mm}$ (mean: $0.22 \mathrm{~mm}$, i.e. $0.055 \mathrm{~mm} / \mathrm{month})$. In this case, the results of the current study $(0.123 \mathrm{~mm} / \mathrm{month})$ fall within the cited interval [5]. In addition, Bratu et al. compared two MIS ${ }^{\circledast}$ subsystems (MIS Seven ${ }^{\oplus}$ : model S with microthreads, and MIS Lance ${ }^{\oplus}$ : model L with a polished neck) in 48 patients. The results showed that marginal bone loss for S implants was $0.21 \mathrm{~mm}$, compared to $0.77 \mathrm{~mm}$ for L implants. The differences in bone loss were statistically significant and resulted from different structures of implant necks [6].

Using Polish implant system Osteoplant Hex ${ }^{\circledast}$ (Type II in the current study), 147 implantations were performed, including 74 flap procedures and 73 that were flapless. For the flap method, bone loss 3 months after implantation reached $0.77 \mathrm{~mm}$, while for the flapless - $1.43 \mathrm{~mm}$ [9].

It must be emphasized that in the current study, in the period before implant loading with prosthetic restoration, no statistically significant differences occurred between the changes in marginal bone status for the two studied types of implants due to their abutments designs. In this period, the closed (submucosal) healing method was applied, without the abutments present, so the consequences of microgap at the level of implant-abutment connection were not revealed at this stage of treatment. The microgap is colonized by bacteria, which adversely affects osseointegration.

The experimental conditions that enabled comparison between the osseointegration processes for both types of implants before prosthetic loading were successfully created. In their experimental model, Weng et al. showed that in dogs with implants placed at the hard bone level and healed with the closed method, the level of marginal bone around DENTSPLY Friadent ANKYLOS ${ }^{\circledR}$ and Nobel Biocare Brånemark System TiUnite ${ }^{\circledast}$ implants did not differ significantly at six months after implantation [10]. It seems, therefore, that regardless of the abutment design, the problem of differences in bone loss around different types of implants would not occur before prosthetic loading in the conditions of closed healing. In such conditions, the access of bacteria responsible for the intensification of peri-implant marginal bone loss is hindered by the mucosal barrier.

Observation of marginal bone around implants after loading implants with prosthetic restorations. In this study, the average time of implant loading with prosthetic restorations was 10.2 months (5.0-26.5 months) for Type I implants, and 10.8 months (5.0-22.1 months) for Type II implants. For both types of implants, marginal bone loss after loading was significantly correlated with time. After loading, the mean marginal bone loss was $0.010 \mathrm{~mm} / \mathrm{month}$ for Type I implants, i.e. $0.12 \mathrm{~mm} /$ year $(\mathrm{p}<0.012)$, while for Type II implants it was $0.030 \mathrm{~mm} / \mathrm{month}$, i.e. $0.36 \mathrm{~mm} /$ year $(\mathrm{p}<0.0001)$. Over the whole period after prosthetic loading, bone loss around Type II implants was significantly higher (by $0.696 \mathrm{~mm}$ ) than that around Type I implants $(\mathrm{p}<0.0001)$, considering also a number of confounding (standardizing) variables.

The results of this study on marginal bone loss related to an implant system with Morse taper (DENTSPLY Friadent ANKYLOS $\left.^{\odot}\right)$ are slightly better $(0.12 \mathrm{~mm}$ /year $)$ than those presented in the literature $[8,11]$.

An evaluation of 1,419 DENTSPLY Friadent ANKYLOS ${ }^{\varpi}$ implants in 313 over 18 months showed that bone loss after loading with prosthetic restorations was $0.2-0.5 \mathrm{~mm}$. The reported results came from 100 dentists from 32 research centres in the USA, Korea, and Taiwan [11]. Chou et al., evaluating over 1,500 DENTSPLY Friadent ANKYLOS ${ }^{\oplus}$ implants during three years after prosthetic loading, found that peri-implant bone loss was $0.15 \mathrm{~mm}$ after the first 12 months, $0.48 \mathrm{~mm}$ after 24 months, and $0.64 \mathrm{~mm}$ after 36 months. The average annual loss in the 3 -year period was $0.2 \mathrm{~mm}[8]$.

The presented assessment of implants with hexagonal implant-abutment connections (mainly MIS ${ }^{\circledast}$ ) does not differ significantly from the results reported by other researchers. It was shown that after prosthetic loading, bone loss around implants with hexagonal connections was $0.36 \mathrm{~mm} /$ years the value close to those found by several authors.

Min-Su et al. described bone loss around 294 MIS $^{\oplus}$ implants with internal hexagonal connection in 93 patients. A year after loading with prosthetic restoration, bone loss was $0.33 \mathrm{~mm}$ [12]. Also, the observation (30 months - nine years, mean observation time 5.3 years) of 181 MIS ${ }^{\circledast}$ implants with internal hexagonal connection, showed that the average marginal bone loss around implants was $2.99 \mathrm{~mm}$ [13]. In another study with 170 Nobel Biocare Replace implants in 31 patients, bone loss a year after loading was $0.4-1.6 \mathrm{~mm}$, and was much higher than that found in the presented study [2].

A macroscopic evaluation of surgically-retrieved DENTSPLY Friadent ANKYLOS ${ }^{\circledR}$ implant (with TissueCare ${ }^{\circledast}$ concept) and a BIOMET $3 \mathrm{i}^{\oplus}$ (with platform switching) implant placed in the same patient, showed that the former osseointegrated better than the latter. Six weeks after implantation, the first bone-to-implant contact was at 0.1$0.3 \mathrm{~mm}$ below the implant neck for DENTSPLY Friadent ANKYLOS ${ }^{\oplus}$, and $0.7 \mathrm{~mm}$ for BIOMET $3 \mathrm{i}^{\oplus}$ [7].

\section{CONCLUSIONS}

1. Marginal bone loss around implants, regardless of the implant-abutment connection design, significantly 
increased with time, both before and after prosthetic loading.

2. Evaluation of the process of marginal bone loss around implants provides grounds to believe that, considering osseointegration, the tapered, conical implant-abutment connection is a significantly better design than the external hexagonal connection.

3. As the process of marginal bone loss is several times faster before loading implants with prosthetic restoration than after loading, it is advisable to consider early loading if the necessary clinical conditions are met.

\section{REFERENCES}

1.Papaspyridakos P, Chen JC, Singh M, Weber HP, Gallucci GO. Success criteria in implant dentistry: a systematic review. J Dent Res. 2012; 91(3): 242-248.

2. Rasouli Ghahroudi AAR, Talaeepour AR, Mesgarzadeh A Rokn AR, Khorsand A, Mesgarzadeh NN, Kharazi Fard MJ. Radiographic vertical bone loss evaluation around dental implants following one year of functional loading. J Dent Teheran Univ Med Sci. 2010; 7(2): 89-97.

3. Hardin J, Hilbe J. Generalized Estimating Equations. Chapman and Hall/CRC, London, 2003.

4. Liang K-Y, Zeger S. Longitudinal data analysis using generalized linear models. Biometrika 1986; 73(1): 13-22.
5. Bratu EA, Olimpiu K, Radu S. Study of bone level around osseointegrated dental implants. MIS News 2007; 19(7): 2-3.

6. Bratu EA, Tandlich M, Shapira L. A rough surface implant neck with microthreads reduces the amount of marginal bone loss: a prospective clinical study. Clin Oral Implants Res. 2009; 20: 827-832.

7.Degidi M, Piatelli A, Shibli JA, Perrotti V, Iezzi G. Bone formation around a dental implant with the platform switching and another with a TissueCare Connection. A histologic and histomorphometric evaluation in man. Titanium 2009; 1(1): 10-17.

8. Chou CT, Morris HF, Ochi S, Walker L, DesRosiers D. AICRG, Part II: Crestal bone loss associated with the ANKYLOS implant: loading to 36 months. J Oral Implantol. 2004; 30(3): 134-143.

9. Kukuła J, Sidorowicz K, Sokalski J. The evaluation of the marginal bone loss in traditional and flapless approach of Osteoplant Hex implants. Implantoprotetyka 2007; 26-27(1-2): 15-19.

10. Weng D, Nagata MJ, Bell M, Bosco AF, de Melo LG, Richter EJ. Influence of microgap location and configuration on the peri-implant bone morphology in submerged implants. An experimental study in dogs. Clin Oral Implants Res. 2008; 19(11): 1141-1447.

11. Morris HF, Winkler S, Ochi S, Kanaan A. A new implant designed to maximize contact with trabecular bone: survival to 18 months. J Oral Implantol. 2001; 27(4): 164-173.

12. Min-Su B, Dong-Seok S, Mi-Ra A. Hyun-Woo L, Heui-Seung J, ImHee S. Retrospective multicenter evaluation of tapered implant with a sandblasted and acid-etched surface at 1 to 4 years of function. Implant Dent. 2011; 20(4): 280-284.

13. Tandlich M, Reizman P, Shapira L. The incidence of the marginal bone loss and failure rate of MIS internal hex implants bearing different types of prosthesis. MIS News 2006; 17: 2-3. 